\title{
Landowner acceptance of wind turbines on their land: Insights from a factorial survey experiment
}

John R. Parkins, Professor

Department of Resource Economics and Environmental Sociology

University of Alberta

515 General Services Building

Edmonton, Alberta, Canada, T6G2H1

jparkins@,ualberta.ca

780-492-3610

Sven Anders, Professor

Department of Resource Economics and Environmental Sociology

University of Alberta

515 General Services Building

Edmonton, Alberta, Canada, T6G2H1

anders1@ualberta.ca

780-492-5453

Jürgen Meyerhoff, Senior Research Fellow

Institute for Landscape Architecture and Environmental Planning

Technische Universität Berlin, Germany

Strasse des 17. Juni 145

10623 Berlin, Germany

juergen.meyerhoff@tu-berlin.de

+493031473322

Monique Holowach, Graduate Student

Department of Resource Economics and Environmental Sociology

University of Alberta

515 General Services Building

Edmonton, Alberta, Canada, T6G2H1

mholowac@ualberta.ca

$780-492-4225$ 


\begin{abstract}
This study uses data from a vignette experiment $(\mathrm{n}=401)$ of large-scale agricultural landowners in western Canada to quantify attributes that enhance acceptance of wind farms on their own land or in their municipality. Analysis addresses the role of community relationships and procedural fairness in the development of wind power. Random effects models indicate that landowners are more accepting of wind power if such projects include local and/or cooperative ownership, compensation payments to neighbouring landowners, and community involvement in the development process. Results suggest that perceived injustices could be lessened if fairness considerations extend beyond monetary gain.
\end{abstract}




\section{Introduction}

Over the last 30 years, wind energy in North America has evolved from a fringe concept into a mainstream and viable source of renewable electricity generation. In 2019, wind power met about $6 \%$ of electricity demand in Canada and represents the largest source of new electric capacity additions; ranking Canada ninth in the world for onshore installed capacity (CanWEA 2020). With improvements to turbine technology and renewable energy infrastructure, the cost of wind energy generation has fallen by roughly $70 \%$ in the past decade. Coupled with favourable policy mandates and economic incentives, the cost-competitive advantage of wind energy along with a wide range of environmental and social benefits has spurred rapid expansion in North American over the past 10-15 years (IPCC 2011; Wiser and Bolinger 2019).

The expansion of wind power across Canada, however, is far from uniform. While the populous provinces of Ontario and Quebec account for over 43\% of national installed capacity, Alberta (a large and less populated province in western Canada) accounts for about 12\% (CanWEA 2020). Although the province is the third-largest producer of electricity in Canada, Alberta's energy sector has long been dominated by fossil fuel extraction (oil, gas, coal), with roughly $90 \%$ of electricity generation based on coal and natural gas in 2018. In addition to these fossil energy resources, Alberta's lightly tapped wind potential presents a significant opportunity for transition to renewable energy sources (Bell and Weis 2009). A study by Barrington-Leigh and Ouliaris (2017) evaluated scenarios for economically viable wind development based on wind speeds of 7 $\mathrm{m} / \mathrm{s}$ at $80 \mathrm{~m}$ above ground. Excluding protected areas, Indigenous lands, reasonable distances from population centres and transmission lines as well as accounting for competing land uses, environmental concerns, and unsuitable locations that reduce the available land base by $75 \%$, the 
analysis found Alberta's wind power generation potential to be around $169 \mathrm{TWh} / \mathrm{year} ; 24 \%$ of Alberta's 2015 energy demand (Barrington-Leigh and Ouliaris, 2017).

Recent market evidence (Wiser and Bolinger 2019; Canadian Energy Regulator 2020) indicates the expansion of wind power generation capacity in Canada is expected to continue, driven by low prices of capacity supply and legislated provincial targets for renewable energy generation (Canada Energy Regulator 2020; Government of Alberta 2020). Research by the U.S. Department of Energy, however, suggests that future wind power projects are destined to face more scrutiny by external stakeholder groups. As the most favourable sites - those with suitable wind resources, and with proximity to transmission networks and electricity customers - become scarcer, the future footprint of wind energy is destined to encroach on communities (especially rural agricultural landowners) without whose engagement and support the necessary siting of new projects may face increasing resistance and outright rejection (e.g., Glen, 2019). The strong potential for opposition to wind farms underscores the need to better understand drivers of wind power acceptance, especially among rural landowners and their affected communities who provide an essential land base for further expansion of wind power.

As a response to the increasing scrutiny of future wind projects, this study conducts a factorial survey with large-scale agricultural landowners who are in a position to host turbines on their land. This sample is distinct from other studies of wind farm development that are often based on general populations. Focusing on landowners is critical to understanding the wind energy development process that requires project developers to obtain landowner consent not only to build turbines, access roads, and transmission lines but also easements from surrounding property owners. Available forms of compensation, complex lease agreements and potential negative externalities of wind turbines beyond the landowners' may thus include neighbour and 
broader community considerations that can complicate an individual landowner's decision to engage in wind power development (Syal et al. 2020).

Another distinctive feature of this study involves the use of a vignette experimental design (Auspurg and Hinz 2015) that presents a departure from often-applied discrete choice experiments in energy and land economics but follows a stream of economic studies on discrimination (Kübler et al. 2018), fairness perceptions (Herz and Taubinsky 2018), ethical judgments (Ambuehl and Ockenfels 2017), and social acceptance (Liebe et al. 2020). In comparison with stated preference methods as the standard for estimating economic trade-offs and marginal utilities in the valuation of different electricity production technologies, vignette experiments emphasize the effect of varying factors on the overall acceptance of a specific scenario when social norms and informal rules are central to the research. As such, vignettes offer an opportunity for landowners to reflect upon alternative ways of developing a wind power project that takes account of neighbours and a broader community context.

There is no shortage of literature documenting public perceptions of and preferences for renewable energy development including preferences for wind power in Canada (Sherren et al. 2019), the United States (Firestone and Kirk 2019) and across Europe (Liebe et al. 2019). Although the general public is broadly supportive of wind power, wind turbines are often met with strong local resistance. Overall, researchers have come to agree that local acceptance of wind turbines, beyond the project phase, hinges on a number of community-specific factors pertaining to procedural justice (Simcock 2016), distributional justice (Larson and Krannich 2016), and trust in energy development processes (Fast and Mabee 2015; Mills et al. 2019).

Economists examine supply-side factors in wind energy development with a focus on technical feasibility and efficiency (Lundquist et al. 2019) and related issues concerning the environmental 
valuation of spatial turbine siting (Lutzeyer et al. 2018; Garcia et al. 2016). These studies also examine the effectiveness of government incentives on the promotion and expansion of wind power (Alagappan et al. 2011), finding that developers respond most positively to cost-based grants in the form of feed-in-tariffs over energy production tax credits when making project development siting decisions. Studies also investigate the negative spillover effects of wind farms in terms of noise and visual effects leading to lower property values (Vyn 2018; Jensen et al. 2014).

Beyond impacts on property owners, several studies examine local factors that may affect the community-level acceptance of wind power developments. The compensation of landowners, while constituting a positive economic benefit, can create perceptions of unfairness or distributional injustice (Fast et al. 2016; Baxter et al. 2013) that may contribute to intracommunity conflicts with landowners as the economic benefits and negative externalities of wind power are spatially segregated (Mills et al. 2019; Meyerhoff et al. 2010). Risk stemming from community and/or rural-urban conflicts have motivated investigations into different forms of community level compensation ranging from direct payments to developer-led investments in community infrastructure or offsetting electricity costs (Baxter et al. 2013; Groth and Vogt 2014). Moreover, several studies (Sovacool and Ratan 2012; Ferguson-Martin and Hill 2011) suggest that local co-ownership structures can boost both landowner and community acceptance of new developments. Finally, several studies focus on the role of community involvement and participation as means for greater transparency, information sharing and balancing complex and diverging stakeholder interests (Jami and Walsh 2017; Jacquet 2015; Groth and Vogt 2014). 
While the existing literature has produced important insights and lessons for wind energy acceptance, the absence of literature on landowner views and how they relate to the broader community that is impacted by wind farms, clearly presents a gap in knowledge.

As a consequence, our results diverge considerably from existing general population studies in Canada (Sherren et al. 2019) and the United States (Firestone and Kirk 2019). While the literature from these studies suggests strong support for climate friendly policies and renewable energy technologies, the results of this paper indicate relatively lower levels of support for renewable energy, and wind power in particular, with limited concern for actions that might address the worsening climate crisis. Thus, a clear distinction between community residents and agricultural landowners is particularly relevant in understanding the opportunities and challenges of wind power development, especially as wind power projects extend further into agricultural landscapes. If in fact concerns over distributive or procedural aspects stand in the way of agricultural landowner acceptance of wind power as much as they appear to influence local residents, then decision-makers need reliable and landowner-specific insights to improve incentives and information systems to overcome such resistance. While several of these factors are prominent in ongoing discussions of renewable energy transition (Rand and Hoen 2017), with attention to community engagement and developer transparency (Firestone et al. 2018), a specific focus on landowner acceptance using experimental techniques is lacking in the literature. To the best of our knowledge, this paper represents an early attempt to quantify factors in landowners' acceptance of wind project development.

\section{Experimental approach}

A landowner's evaluation of potential wind power projects is likely to involve a large number of decision criteria that go beyond easily quantifiable attributes such as monetary payments, turbine 
or farm size, noise level, proximity and other project attributes that are commonly entered into choice or conjoint experimental designs. The integration of broader social factors into choice designs and the causal inference of preferences is less straight forward. Consequentially, most multifactorial survey experiments distinguish questions about the relevance of social factors, including perceptions of fairness or justice, attitudes towards wind energy or individuals' social norms, from the process of preference elicitation. Separating these components of preference elicitation is a limitation of stated preference methods.

As an alternative method, vignette experiments (VEs) can account for those social factors within short and descriptive scenarios based on relevant decision factors. Respondents in VE studies typically face multiple vignettes in the form of between-subject designs and are then asked to evaluate each scenario according to their level of acceptance, support, or perceived fairness. The randomization of discrete and related attributes, presumed to be important determinants of respondents' decision making, enables the identification of causal attributes based on theory-led experimental designs and contextual factors generated by the researcher (Auspurg and Hinz 2015).

VEs differ from stated-preference methods in that they do not request respondents to make choices or rank alternatives from which trade-offs are derived. Instead, VEs provide an indirect measurement of individuals' evaluations of vignette attributes as part of a scenario, where attribute trade-offs lower the potential of social desirability bias (Auspurg and Jäckle 2017). As such, VEs allow researchers to estimate the relative importance of a set of attributes and levels in an individual's evaluation of an experimentally created context (Hainmueller et al. 2015). 


\section{Study design}

The dataset was drawn from an online survey conducted between December 2018 to March 2019 involving 401 rural (agricultural) landowners in the Province of Alberta (Canada). Potential participants were recruited from the members of an established online panel of agricultural operators maintained by the market research firm, Kynetec (Guelph, Canada). Study participants were recruited from among all Alberta panel members $(n=3000)$ that provided permission to Kynetec to conduct surveys online. Qualifying farm operators with sales of more than $\$ 10,000$ CAD per year and landownership of at least ten acres were sent an email invitation to take part, along with reminder emails over the course of the data collection period. To achieve our final list of respondents, Kynetec also utilized telephone recruitment of panel members where phone numbers were pulled randomly from the database. Eligible landowners were at least 18 years of age, owned over five acres of land in Alberta, and were the decision maker $(n=389)$ or one of the primary decision-makers $(n=12)$ in the farming operation. Quotas were put in place to ensure geographic coverage and participants received \$20 CAD for completing the 20-minute questionnaire.

Although there are random elements to the construction of this sample, this is a non-probability sample, reflecting the challenges and investment required in securing the participation of these large-scale agricultural businesses. Therefore, we need to maintain caution in generalizing results of this study to the population of agricultural producers in Alberta. The study received human ethics research approval at the University of Alberta (Pro00084046).

Vignettes were comprised of six attributes, each expressed in three levels (Table 1). These attributes were determined based on a previous study (Afanasyeva et al. 2022) involving extensive conversations with landowners as well as insights from other studies that take account 
of procedural and distributional concerns (Walker and Baxter 2017). First, we consider wind power project location and proximity to homes and the community to explore the complex relationship between proximity to wind farms and support for wind power (Jacquet 2012; Baxter et al. 2013). Baxter et al. (2013) find that survey respondents in Ontario (Canada) had more positive attitudes towards the installation of wind energy projects in the province compared to locations within their own municipality. However, people living in a community with turbines had a more positive attitude towards wind power in general compared to residents in a turbine free community. Since those insights are drawn from a sample of community residents, results are not directly applicable to this study of rural landowners in Alberta, leaving open the possibility that our results may differ. We model the proximity of wind project location ranging from "on the other side of your county", to "on your neighbours' property", and "on your property".

[Table 1 here]

Second, compensation is an important factor driving local acceptance of wind farms (Christidis et al. 2017; Lienhoop 2018; Jørgensen et al. 2020). Jacquet (2012) suggests that compensation may trump concerns about proximity, especially when monetary incentives are distributed among the entire community and beyond affected individuals. This finding is confirmed by Hoen et al. (2019). However, the ability of compensation schemes to overcome community resistance is not undisputed when it comes to perceptions of process fairness as localized monetary benefits can be construed as bribery (Aitken 2010; Kerr et al. 2017). In this context, distributive justice (defined as the fair distribution of perceived burdens and public benefits derived from wind projects) comes into play (Langer et al. 2016). Proposed compensation schemes in the literature are diverse and range from direct financial compensation to adjacent property owners, proximity- 
based compensation to property owners, and community payments and/or (infrastructure) investments (Garcia et al. 2016; Lienhoop 2018). We adapt this evidence and model compensation based on aspects of its distributive fairness ranging from landowners' neighbours "not receiving any compensation", "also receiving some compensation", to "receiving equal compensation amounts as the landowner hosting the turbines".

Third, across Europe, evidence suggests a strong and positive shift in the acceptance of wind power when communities are offered opportunities for local ownership (Cashmore et al. 2019; Musall and Kuik 2011). However, the North American experience differs considerably, as local ownership remains rare (Rand and Hoen, 2017). Research conducted in Ontario indicates that while community ownership remains low, it can have positive effects on wind power acceptance (Fast et al. 2016; Walker and Baxter 2017). We model ownership options in the form of "your municipality", "a local cooperative", to the common arrangement involving "a private utility company".

Fourth, procedural justice involves the perceived fairness of the planning process in terms of public inclusion, information sharing and the ability to influence decision-making around wind project siting. These procedures are often identified as an important factor in the acceptance of wind power by local residence (Simcock 2016; Jørgensen et al. 2020). Aitken (2010) suggests that increasing participation in the decision making and planning process can increase the level of acceptance through higher perceived procedural justice and thus, higher perceived fairness of the outcome. Several recent studies confirm the link between the inclusions of the local community in decision making and increased acceptance of wind projects (Liebe and Dobers 2019; Mills et al. 2019). We adapt this factor and model community inclusion in spatial terms as 
including "all county residents", "only the neighbours who are directly affected" or "only the landowners with turbines" in the planning process.

Fifth, closely linked to inclusion is the capacity for local residents (and landowners) to influence or have a say in the final outcome of a planning process. This factor represents a second element of procedural justice. Walker and Baxter (2017) summarize that changes in policies imposing restrictions on local influence on turbine siting decisions in Canada have significantly increased community opposition (Fast et al. 2016, Baxter et al. 2013). Similar results have been reported for studies across Europe (Lienhoop 2018) and in the Unites States (Firestone et al. 2018). We model the degree of community influence in the siting decision process as the ability to "express concern about the project", “express concern and potentially sway", or "have direct say (e.g. voting)" on the proposed project.

Finally, access to information is the third element of procedural justice. Information provision and procedural transparency have been identified by several studies to impact perceived fairness leading to more positive attitudes and acceptance of renewable energy and wind project development processes at the local level (Musall and Kuik 2011; Firestone et al. 2012). Using a discrete choice experiment, Brennan and Van Rensburg (2016) showed that two thirds of respondents preferred access to $100 \%$ of information even if that had a negative impact on compensation levels. Moreover, required compensation levels were found to be lower if a community representative was appointed to the decision-making body. We adapt this concept and model the impacts of transparency and access to information on landowner preferences for wind power projects ranging from lease payments and compensation amounts that "will be confidential", "will be available to some affected" and "will be publicly available". As a basis of 
comparison, the status quo attribute levels for wind power development in Alberta are noted in Table 1.

Based on the six attributes and their three levels we generate a full factorial design of 729 unique vignettes. Next, we created a fold-over design that allows for two-way interactions so that attributes vary independently of each other within and across vignettes. The final design comprised 144 vignettes. Out of this basket of vignettes, for each respondent six vignettes were randomly drawn (without replacement) to avoid learning and order effects in vignette ratings (Auspurg and Jäckle 2017). To prevent fatigue, the number of vignettes was confined to six for each respondent. With 401 participating landowners each vignette was rated approximately 17 times resulting in a total of 2406 evaluations.

To provide a sufficient range of vignette judgments, and thus avoid the risks of censored responses and outliers, the vignette structure asked participants to rate each vignette on an 11point scale from -5 to +5 where end points were described textually as completely unacceptable to complete acceptable (Kübler et al. 2018).

Drawing from the stated preference literature (Mariel et al. 2021), all participants read a brief script at the beginning the experiment. The script informed respondents about the hypothetical nature of the task (Penn and $\mathrm{Hu}, 2018$ ) and set a baseline of understanding. Based on extensive interviews with landowners prior to this study, the script invited respondents to set aside concerns about financial feasibility, environment and health impacts, which were found to be lesser concern to landowners than the attributes identified within the experiment design. The following script was provided to participants in advance of the vignettes shown in Figure 1. 
"Although these are hypothetical scenarios and some may not seem like "real" options, please respond as if you were actually in that situation. The results from this section may be used to guide policy makers and help make Alberta's energy system work better for rural communities."

"You may have more thoughts on wind energy, and we will be asking you more about that later in the survey. For the purposes of this scenario task, please assume that any concerns related to financial feasibility, impacts on the environment and wildlife, and human health will NOT be an issue. In other words, these described wind farms will be safe (for humans and animals), profitable, and have enough wind. Also, for these scenarios, assume the following benefits:

- A local wind farm will generate local tax revenue for your county/municipality,

- Landowners hosting wind turbines will receive substantial lease payments.

[Figure 1 here]

After the vignette experiment, the survey included several questions that allowed us to quantify determinants of wind energy acceptance that are independent of the vignette experiment. Questions included landowner experience with wind turbines, their self-rated knowledge of wind energy, as well as levels of agreement with publicly debated concerns surrounding wind energy (Jørgensen et al. 2020, Simcock 2016). These include noise pollution, effects on wildlife and bird populations, aesthetic landscape effects as well as concerns regarding community conflict and rising electricity prices resulting from the expansion of wind energy.

To measure social norms as expressed through unwritten rules or expectations, we adapted questions developed in the literature (Farrow et al. 2017). With a focus on famer-specific environmental values (Silvasti 2003), we measured local and global environmental concerns and farm-level climate change concerns (Davidson et al. 2019); adapting established scale-question formats to our landowner subject pool. We also measured trust in community and energy sector stakeholders (Firestone et al. 2012) as well as respondent political affiliation (Davidson et al. 
2019). In addition to socio-demographics, farm size and farm type, we measured other attitudinal and perception questions using five-point scales from 1 (strongly disagree) to 5 (strongly agree).

Given the multi-level structure of our data, with a focus on vignette ratings as the dependent variable, we employed a random effects (RE) model to account for the nested structure of the data at the respondent level and the presumed heterogeneity among respondents (Atzmueller and Steiner 2010). A RE model specification also allows for the inclusion of second order respondent characteristics (Model 2 in Table 4). As the participating landowners were recruited from within the same geographical region and industry (agriculture), we assume that the respondents did not differ in their understanding of the acceptance response. In other words, all landowners were assumed to evaluate a particular wind power scenario as 'completely acceptable' if it fully met their preferences, thus obviating the need to correct differences in response scales, commonly known as "differential item functioning," or DIF (Greene et al. 2021) at the model estimation stage. Using the statistical software package Stata, we estimate random intercept models assuming that participants will express different acceptance thresholds for vignettes with varying attribute levels (Auspurg and Hinz 2015). We use likelihood-ratio tests to verify preferred model specifications against ordinary least square models that will result in biased standard errors. The dataset and coding utilized to derive results below are available at the Scholars Portal Dataverse repository (Parkins et al. 2021).

\section{Results}

Descriptive statistics in Table 2 provide a snapshot of survey respondents, including characteristics of land management and related farm structure and farm type variables. Our respondents are reflective of larger, commercial crop and livestock farms (Table 2). The average size of operations in the sample was 2982 acres relative to an average of 1237 acres in the farm 
census, thus making the survey data more reflective of larger and more commercially oriented farm operations in Alberta (Statistics Canada 2016). Respondents were mostly male (90\%) within this group of larger farm operators, compared with $31 \%$ female operators among all farms in the province. Data from the Alberta farm census (Government of Alberta 2018) also indicates that roughly $45 \%$ of farm operations are managed in partnership or as a corporation of two or more family members. Regarding the age of respondents, the median age falls within the 55-64 years old category, which is in line with the average age of farm operator, at 55.7 years (Government of Alberta, 2018). The distribution of farm operators is also compared here between sample statistics and (census) data: $65 \%$ (57\%) aged 55 or older, $31 \%(35 \%)$ being 35 54 years old, and 3\% (9\%) being 34 years of age or younger.

While our sample may not be representative of the population of rural Alberta agricultural landowners, it does offer unique insights into this particular group of large-scale land owners who are in a position to host wind turbines on their land. These landowners represent a point of view and a position of authority about how their land will be utilized and how it will contribute to, or inhibit, the development of renewable energy landscapes. The insights gleaned here warrant further exploration of comparable datasets in other parts of North America.

[Table 2 here]

Against the background of a fossil fuel dominated energy sector and its long-standing ties to rural landowners, the majority of respondents expressed the importance of the energy sector to them ( $\mu$ 4.09, 5-point scale). The likelihood of installing renewable energy and knowledge of wind energy, however, were relatively low $(<3.0)$. Grounded in conservative political views and ties to the regions oil and gas industry, concerns for climate change were found to be relatively low. For example, in response to the statement that "we still do not know for sure whether 
climate change is real or caused by humans" $62 \%$ of respondents agreed or strongly agreed with this statement ( $\mu 3.55)$. Only $28 \%$ of landowners agreed that adopting renewable energy will help reduce climate change impacts $(\mu 2.52)$.

Regarding respondents' support for wind power relative to other sources of energy, results in Table 3 confirm landowners' strong support for the regional fossil fuel economy. A striking result is the fact that support for wind energy is situated among coal (to be phased out) and nuclear energy (not present in the province) as the least supported energy sources. These initial results clearly indicate that our sample of rural landowners remains very skeptical of renewable energy in the context of climate change mitigation or the adoption of renewables as the future of economic activity in the province. With this context in mind, and against the evidence from general population data in other studies (e.g., Sherren et al. 2019; Firestone and Kirk 2019), further development of wind farms in Alberta may face stiff resistance from rural landowners.

[Table 3 here]

\section{Vignette evaluations}

Figure 2 gives a first impression of landowners' evaluations of wind power projects by contrasting the distributions of vignette ratings of (very) strong supporters of oil and gas ( $\mu$ 4.22, $\sigma, 3.08)$, (very) strong supporters of wind energy $(\mu 6.36, \sigma, 2.91)$, and those who stated equally strong support for both energy sources $(\mu 7.07, \sigma, 3.06)$. Consequently, the mean acceptance level between the three landowner groups are highly statistically significant based on a two-sided t-tests. There were 303 times when vignettes were given a rating of 'completely unacceptable' by supporters of oil and gas, whereas 36 scenarios were rated to be 'completely acceptable'. In contrast, landowners who expressed strong support for both fossil fuel and wind energy sectors gave 142 scenarios the highest rating. Given the small number of exclusive supporters of wind 
energy among landowners $(n=60), 21$ scenarios were rated as completely acceptable. Other landowners were found to state relatively consistent levels of acceptability with a slightly larger number of ratings in the range of marginal to positive acceptability between 8 and 11 . Finally, there was some evidence of non-cooperation with the experiment, where 30 respondents did not follow instructions and provided the same response at -5 (completely unacceptable) for all six vignettes that were presented to them. Analysis indicates little difference in results when these participants are excluded. Therefore, we selected to include all responses in the results presented below.

Based on the descriptive statistics in Table 2, a majority of landowners shows limited support for wind energy or concerns for a climate-change-induced need to shift away from fossil fuel energy sources. This perspective is also observed in Figure 2 where the majority of vignettes were rated below the midpoint of 0 (i.e., $45 \%<0,42 \%>0$, and the remainder at the midpoint). The descriptive analysis thus points to important differences in wind energy acceptance based on the underlying preferences of landowners.

[Figure 2 here]

Since each landowner evaluated six vignettes, Table 4 presents the results of two random effects (RE) regressions models. Model 1 is based on the vignette attributes (Table 1). A fixed effects specification of model 1 was estimated as a robustness check and yielded stable coefficient estimates in both sign and magnitude. Model 2 expands the initial model specification with landowners' characteristics deemed relevant to acceptance ratings. For both models, likelihoodratio tests indicate that the RE model specifications are highly preferred over ordinary least square regressions. Moreover, attribute interactions between vignette variables of interest (e.g., turbine proximity and compensation) were not significant and we therefore only present the main 
attribute effects. Intra-class correlation coefficients of 0.625 and 0.605 , respectively, indicate a high correlation among the six vignette evaluations per landowner. Coefficient estimates for each attribute are presented relative to the status quo for wind power development in Alberta.

Across models, compensation has the strongest effect on wind power scenario acceptance levels. Measured against no compensation for neighbours within a radius of $20 \mathrm{~km}$, the most preferred attribute involves neighbours of turbine-hosting landowners to also receive some compensation (.907). Note that this effect is stronger than the option for equal compensation levels between the hosts and its surrounding landowners. The result that a gradient of compensation between host and surrounding neighbours is preferred reflects a preference for 'fairness' in a proximity-based compensation mechanism highlighted in previous studies (Walker and Baxter 2017; Mills et al., 2019). Similarly, procedural justice emerges as another strong and robust effect estimate. Relative to the inclusion of the contracting parties in wind energy development, landowners' acceptance not only hinges on the inclusion of neighbouring landowners that will be directly affected (.723), but also the inclusion of 'all county residents' with an effect size that was slightly lower (.584) confirmed by a Wald test statistic of 0.248 . Yet, landowner decisions appear to consider the impact of their choices on overall neighbour and community relations that reflect on the desire for fairness in the energy infrastructure development process. This result was also found in Liebe et al (2019). The role of ownership structure on landowner acceptance is also revealing. In Western Canada (and Alberta), where large-scale corporate utilities own the majority of wind energy infrastructure, we find results in line with Christidis et al. (2017) that landowners express a clear preference for more local municipal ownership (.282) and more equitable cooperative ownership (.418). Controlling for economic and fairness-related factors, proximity is less influential on scenario acceptance. The magnitude of marginal effects for a perceived 'fair' level of compensation relative to the placement of wind turbines on adjacent or 
distant land suggest that the placement of wind energy developments plays a minor role in landowners' evaluation of potential projects.

Differences between landowner characteristics (and farm operations) as a source of heterogeneity may also influence the evaluation of wind energy scenarios. Therefore Model 2 includes a series of control variables including sociodemographic and land-use factors, landowners' beliefs, knowledge and political orientation. Based on these control variables in Model 2, our results also confirm the role of landowner social norms as well as political orientation that are drivers of landowner acceptance of wind energy on their land. Regarding norms, vignette ratings of respondents' who agreed with the statement 'For the most part, my local community would be excited about a new wind farm' were 1.878 points above average. Being politically conservative shapes landowner acceptance levels with vignette scenario ratings 0.574 scale points higher. This positive coefficient among conservatives may reflect a desire for energy independence and autonomy, a topic that we address in more detail below. While being a factor in many citizen-focus studies on wind energy (Jørgensen et al. 2020), previous experience with wind turbines has no effect on landowners' ratings of vignette scenarios, although selfreported knowledge of wind energy is significant and positive. Overall, although several landowner characteristics matter to their vignette ratings, the effect of scenario attributes and thus landowner decision-making around wind energy development on their land remains robust between both model specifications in Table 4 .

One final comment on vignette attribute variables involves the question of influence. Results indicate a negative coefficient for expressing concern and potentially swaying the outcome of a project (-.257). Given the potential for deep conflict between neighbours who disagree on the development of new wind farms in a community, this outcome reflects a general sense that 
neighbours (or all county residents) should not be in full control over the final decision of a project. Being able to express concern is warranted but more control over project outcomes is less desirable.

\section{Discussion and conclusion}

Against the backdrop of strong support for fossil fuel extraction, and limited concern for climate change or its mitigation policies, low levels of support for wind energy appears to stand in the way of landowner acceptance of wind energy in the province. Conventional pathways for the expansion of renewables across the region include large-scale private investment by corporate utility companies, no compensation for neighbouring landowners or the community, limited means for information sharing or inclusion in siting and designing new projects. All of these conventions run counter to landowners' acceptance of wind power in this study.

With this context in mind, what are the characteristics of wind energy development that would render a project more acceptable to rural landowners? Results from this study identify several procedural and design elements that can enhance expansion of wind energy through landowner support. To illustrate these elements, we provide an 'optimal design' based on the estimated attribute coefficients reported in Table 4 (underlined) that yield the highest levels of acceptability by surveyed landowners.

There is an opportunity for a local cooperative to develop a wind farm on the other side of your county. With projects like this, neighbours within $20 \mathrm{~km}$ of a turbine will also receive some compensation. Only the neighbours who are directly affected will have the opportunity to express concern about the project. Detailed financial reporting including compensation rates will not be publicly available.

While this 'ideal scenario' suggests several implications for advancing renewable energy policy for oil-rich Western Canada, it also reflects the general reluctance of rural landowners to accept 
wind turbines on their land and on the surrounding landscape. In short, landowners don't want turbines on their property, not even close to it, but want to receive compensation. Yet we also see a desire for more access to information and more inclusion in decision making that could render wind farms more acceptable to these landowners.

A note of caution in this interpretation is also warranted, however. The analysis we present has limitations in that our survey participants stretch across a region that is the size of countries. Despite their uniform evaluation of scenarios, some landowners are separated by more than 1000 $\mathrm{km}$ and respondents thus may differ in characteristics beyond the scope of this paper. As is common to experimental valuations, although our sample of landowners found the design of certain scenarios acceptable, in practice, the work of designing and siting wind energy projects is a complex process between multiple stakeholders involving other infrastructure (e.g. powerlines) and design elements extending beyond the scope of this study. In this sense, the findings of this study inform possible avenues toward landowner acceptance of wind energy, with insights into key attributes that are likely to matter in the development and implementation of new wind farms.

Consistent with the broader wind acceptance literature in North America and Europe, our results indicate that landowners in Canada prefer forms of local, municipal or cooperative ownership (Christidis et al. 2017) that include 'fair' forms of compensation beyond traditional lease payments to landowners who host energy infrastructure (Walker and Baxter 2017). Results also show the importance of inclusive procedures. Greater transparency and inclusion beyond the private contracting parties are preferred by landowners as much as they are by members of the public (Mills et al. 2019). These results are consistent with studies such as Hoen et al. (2019) who identify fairness as a key predictor of support for wind energy amongst those who live in 
and around wind farms. The study presented here adds further support for this finding in that large-scale agricultural landowners as potential hosts of wind turbines are also keenly interested in fairness aspects of project development.

Regarding proximity, location attributes and compensation, the published literature offers a complex set of insights. While proximity was negatively associated with landowner support in some studies (Jacquet 2012), other evidence points to a reversed relationship (Mills et al. 2019). Similar to other studies that identify complexity between compensation variables and hosting decisions (e.g., Hoen et al. 2019), our results suggest a complex interplay between proximity, compensation and ownership structure. While this study confirms a positive relationship between distance and acceptance of wind turbines, local ownership and more equitable compensation of proximate wind development are also (arguably more important) factors in determining landowner acceptance of wind farms. One reason for this finding may be that wind energy remains relatively new within North American landscapes, and landowners have limited experience living within turbine-dominated landscapes more commonly associated with Europe (Rand and Hoen 2017).

In addition to these insights, there are two key areas of particular interest. First, regarding forms of ownership, a preference for local cooperative structures was somewhat unexpected, but perhaps not entirely surprising. Despite extensive attention to community energy in the published literature (Simcock 2016), there are very few examples of cooperative or community owned energy production in Alberta. Existing oil and gas infrastructure on agricultural land is almost entirely owned by private companies, and there are only a small number of community owned energy projects in the province. While landowners preferred a form of ownership in the production of energy that is very rare within the region, the agricultural community does have a 
long history of cooperative organization for production and transportation of agricultural commodities. This history extends to cooperative ownership of rural electricity transmission lines is also well (MacArthur, 2016). These experiences with cooperative ownership in other sectors may bode well for cooperative structures on the emerging supply-side of electricity generation, especially as energy supply becomes more decentralized in the years ahead.

Second, the compensation attribute within the vignette reveals an interesting pattern of responses. One might assume that respondents would seek to maximize compensation payments, which would reflect the idea that 'other residents living nearby will receive equal compensation with the landowner'. Although this option was preferred over the 'no compensation' option (which was expected), it is interesting to observe that most respondents preferred 'some compensation' for neighbours. This outcome tells us two things about the results of this study. First, landowners appear to care about relationships with their neighbours and thus intend to promote 'neighborliness' through shared benefits from wind paper. Second, respondents recognize that hosting a turbine on their land comes with costs, such as inconvenience and remediation risks, suggesting that landowners who host turbines should be compensated more than neighbours. This issue is a question of fairness and links directly to distributive justice as a key element of acceptability in wind farm developments.

Finally, there are several insights involving control variables. For example, with regard to political orientation, we find that respondents with more conservative views also tend to rate vignettes more positively conservative views are positively correlated with vignette acceptance. These results may signal an opportunity for positive messaging to landowners about renewable energy development that is based on moral frames. Although there is emerging research in environmental psychology on moral framing (Hurst and Stern 2020), the integration of different 
message frames within economic experiments may yield valuable insights. Particularly within politically conservative jurisdictions like Alberta, more politically liberal framing (e.g., fairness or harm) may have less traction than politically conservative framing (e.g., independence or authority). Designing vignettes to reflect these divergent moral frames can lead to insights around how we talk about wind power and what we value in fostering dialogue on renewable energy more broadly.

\section{Acknowledgement}

We are grateful to Manuela Zindler for assistance in preparing tables and organizing published literature. Special thanks to our research participants who provided valuable insights into their experiences with wind farms. We also thank the anonymous journal reviewers who helped to improve the overall quality of this paper. Funding for this study was provided by the Social Science and Humanities Research Council (Project number 435-2017-0281).

\section{References}

Afanasyeva, Aleksandra, Debra J. Davidson and John R. Parkins. 2022. "Wind energy development and anti-environmentalism in Alberta, Canada.", In Handbook of Antienvironmentalism, ed. David T. Tindall, Mark Stoddart and Riley Dunlap. Edward Elgar. Aitken, Mhairi. 2010. "Wind power and community benefits: challenges and opportunities." Energy Policy 38 (10): 6066-6075.

Ambuehl, Sandro, and Alex Ockenfels 2017. "The Ethics of Incentivizing the Uninformed: A Vignette Study.” American Economic Review 107: 91-95.

Alagappan, L., R. Orans and C. Woo. 2011. "What drives renewable energy development?" Energy Policy 39(9): 5099-5104. 
Atzmüller, Christiane and Peter M. Steiner. 2010. "Experimental vignette studies in survey research." Methodology, 6: 128-138.

Auspurg, Katrin and Thomas Hinz. 2015. "Multifactorial Experiments in Surveys: Conjoint Analysis, Choice Experiments, and Factorial Surveys". In Experimente in den Sozialwissenschaften. 1. Aufl. Baden-Baden: Nomos, eds. Marc Keuschnigg and Tobias Wolbring, 291-315. Nomos.

Auspurg, Katrin, and Annette Jäckle, A. 2017. "First equals most important? Order effects in vignette-based measurement." Sociological Methods and Research 46 (3): 490-539.

Barrington-Leigh, Christopher, and Mark Ouliaris. 2017. "The renewable energy landscape in Canada: a spatial analysis." Renewable and Sustainable Energy Reviews 75: 809-819.

Baxter, Jamie, Rakhee Morzaria and Rachel Hirsch. 2013. "A case-control study of support/opposition to wind turbines: Perceptions of health risk, economic benefits, and community conflict." Energy Policy 61: 931-943.

Bell, Jeff, and Tim Weis. 2009. Greening the grid: Powering Alberta's future with renewable energy. Drayton Valley: AB: Pembina Institute.

Brennan, Noreen, and Thomas M. Van Rensburg. 2016. "Wind farm externalities and public preferences for community consultation in Ireland: A discrete choice experiments approach." Energy Policy 94: 355-365.

Canada Energy Regulator. 2020. Canada's Energy Future 2018: Technology Case Results. Ottawa: Government of Canada. Available at: https://www.cer-rec.gc.ca/en/dataanalysis/canada-energy-future/2018/chapter-4-technology-case-results.html CanWEA (2020). Installed Capacity. Ottawa: Canadian Wind Energy Association Available at: https://canwea.ca/wind-energy/installed-capacity/ 
Cashmore, Matthew, David Rudolph, Sanne Vammen Larsen and Helle Nielsen. 2019.

"International experiences with opposition to wind energy siting decisions: lessons for environmental and social appraisal." Journal of Environmental Planning and Management 62 (7): 1109-1132.

Christidis, Tanya, Geoffrey Lewis and Philip Bigelow. 2017. "Understanding support and opposition to wind turbine development in Ontario, Canada and assessing possible steps for future development." Renewable Energy 112: 93-103.

Davidson, Debra J., Curtis Rollins, Lianne Lefsrud, Sven Anders and Andreas Hamann. 2019. “Just don't call it climate change: climate-skeptic farmer adoption of climate-mitigative practices." Environmental Research Letters 14 (3): 034015.

Farrow, Katherine, Gilles Grolleau and Lisette Ibanez. 2017. "Social norms and proenvironmental behavior: a review of the evidence." Ecological Economics 140: 1-13.

Fast, Stewart, and Warren Mabee. 2015. "Place-making and trust-building: the influence of policy on host community responses to wind farms." Energy Policy 81: 27-37.

Fast, Stewart, Warren Mabee, Jaime Baxter, Tanya Christidis, Liz Driver, Stephen Hill, J.J. McMurtry and Melody Tomkow. 2016. "Lessons learned from Ontario wind energy disputes." Nature Energy 1 (2): 15028.

Ferguson-Martin, Christopher, J., and Stephen D. Hill. 2011. “Accounting for variation in wind deployment between Canadian provinces." Energy Policy 39 (3): 1647-1658.

Firestone, Jeremy, Willett Kempton, Meredith Blaydes Lilley and Kateryna Samoteskul. 2012. "Public acceptance of offshore wind power: does perceived fairness of process matter?" Journal of Environmental Planning and Management 55 (10): 1387-1402. 
Firestone, Jeremy, Ben Hoen, Joseph Rand, Debi Elliott, Gundula Hübner and Johannes Pohl. 2018. "Reconsidering barriers to wind power projects: community engagement, developer transparency and place." Journal of Environmental Policy \& Planning 20 (3): 370-386.

Firestone, Jeremy, and Hannah Kirk. 2019. “A strong relative preference for wind turbines in the United States among those who live near them." Nature Energy 4 (4): 311-320.

Garcia, Jorge H., Todd L. Cherry, Steffen Kallbekken and Asbjørn Torvanger. 2016. "Willingness to accept local wind energy development: does the compensation mechanism matter?" Energy Policy 99: 165-173.

Glen, Barb. 2019. "Wind power losing love in southern Alberta." The Western Producer. Available at: https:/www.producer.com/news/wind-power-losing-love-in-southern-alberta/ Government of Alberta. 2018. Census of Agriculture Provincial Profiles: Alberta Farm and Farm Operator - Highlights. Available at: https://open.alberta.ca/publications/census-ofagriculture-provincial-profiles-alberta-farm-and-farm-operator-highlights

Government of Alberta. 2020. Renewable Energy Legislation and Reporting. Available at: https://www.alberta.ca/renewable-energy-legislation-and-reporting.aspx Greene, William H., Mark N. Harris, Rachel J. Knott and Nigel Rice. 2021. "Specification and testing of hierarchical ordered response models with anchoring vignettes." Journal of the Royal Statistical Society Series A, 184: 31-64.

Groth, Theresa M., and Chrstine Vogt. 2014. 'Residents' perceptions of wind turbines: an analysis of two townships in Michigan.” Energy Policy 65: 251-260.

Hainmueller, Jens, Dominik Hangartner and Teppei Yamamoto. 2015. "Validating vignette and conjoint survey experiments against real-world behavior." Proceedings of the National Academy of Sciences of the United States of America 112 (8): 2395-2400. 
Herz, Holger, and Dmitry Taubinsky. 2018. "What Makes a Price Fair? An Experimental Study of Transaction Experience and Endogenous Fairness Views.” Journal of the European Economic Association 16 (2): 316-352.

Hoen, Ben, Jeremy Firestone, Joseph Rand, Debi Elliot, Gundula Hübner, Johannes Pohl, Ryan Wiser, Eric Lantz, T. Ryan Haac and Ken Kaliski. 2019. "Attitudes of US wind turbine neighbors: Analysis of a nationwide survey.” Energy Policy 134, 110981.

Hurst, Kirstin, and Marc J. Stern. 2020. "Messaging for environmental action: The role of moral framing and message source.” Journal of Environmental Psychology 68, 101394.

Intergovernmental Panel on Climate Change (IPCC). 2011. Special Report on Renewable Energy Sources and Climate Change Mitigation. New York: Cambridge University Press.

Jacquet, Jeffrey B. 2012. "Landowner attitudes toward natural gas and wind farm development in northern Pennsylvania.” Energy Policy 50: 677-688.

Jacquet, Jeffrey B. 2015. "The rise of private participation in the planning of energy projects in the rural United States?" Society \& Natural Resources 28 (3): 231-245.

Jami, Anahita A., and Philip R. Walsh. 2017. "From consultation to collaboration: A participatory framework for positive community engagement with wind energy projects in Ontario, Canada. Energy Resource and Social Science 27: 14-24.

Jensen, Cathrine Ulla, Toke Emil Panduro and Thomas Hedemark Lundhede. 2014. "The Vindication of Don Quixote: The Impact of Noise and Visual Pollution from Wind Turbines." Land Economics 90 (4): 668-682.

Jørgensen, Marie Leer, Helle Tegner Anker and Jesper Lassen. 2020. “Distributive fairness and local acceptance of wind turbines: The role of compensation schemes." Energy Policy 138:

111294. 
Kerr, Sandy, Kate Johnson and Stephanie Weir. 2017. "Understanding community benefit payments from renewable energy development.” Energy Policy 105: 202-211.

Kübler Dorothea, Julia Schmid and Robert Stüber. 2018. "Gender discrimination in hiring across occupations: A nationally-representative vignette study.” Labour Economics 55, 215-229.

Langer, Katharina, Thomas Decker, Jutta Roosen and Klaus Menrad. 2016. “A qualitative analysis to understand the acceptance of wind energy in Bavaria." Renewable and Sustainable Energy Reviews 64: 248-259.

Larson, Eric C., and Richard S. Krannich. 2016. ““'A Great Idea, Just Not Near Me!” Understanding Public Attitudes About Renewable Energy Facilities.” Society \& Natural Resources 29 (12): 1436-1451.

Liebe, Ulf, Peter Preisendörfer, Heidi Bruderer Enzler. 2020. “The social acceptance of airport expansion scenarios: A factorial survey experiment." Transportation Research, Part D, 84, 102363.

Liebe, Ulf, Anna Bartczak and Jürgen Meyerhoff. 2019. “A turbine is not only a turbine: The role of social context and fairness characteristics for the local acceptance of wind power." Energy Policy 107, 300-308.

Liebe, Ulf, and Geesche M. Dobers. 2019. "Decomposing public support for energy policy: What drives acceptance of and intentions to protest against renewable energy expansion in Germany?" Energy Research and Social Science 47, 247-260

Lienhoop, Nele. 2018. "Acceptance of wind energy and the role of financial and procedural participation: An investigation with focus groups and choice experiments.” Energy Policy 118, $97-105$. 
Lundquist, J. K., K.K. DuVivier, D. Kaffine and J.M. Tomaszewski. 2019. "Costs and consequences of wind turbine wake effects arising from uncoordinated wind energy development." Nature Energy 4 (1): 26-34.

Lutzeyer, Sanja, Daniel J. Phaneuf and Laura O. Taylor. 2018. "The amenity costs of offshore wind farms: Evidence from a choice experiment." Energy Economics 72: 621-639.

MacArthur, Julie L. 2016. Empowering electricity: Co-operatives, sustainability, and power sector reform in Canada. Vancouver: UBC Press.

Mariel, Petr, David Hoyos, Jürgen Meyerhoff, Mikolaj Czajkowski, Thijs Dekker, Klaus Glenk, Jette Bredahl Jacobsen, Ulf Liebe, Søren Bøye Olsen, Julian Sagebiel, Mara Thiene. 2021. Environmental Valuation with Discrete Choice Experiments: Guidance on Design, Implementation and Data Analysis. Springer.

Meyerhoff, Jürgen, Cornelia Ohl and Volkmar Hartje. 2010. "Landscape externalities from onshore wind power." Energy Policy 38 (1): 82-92.

Mills, Sarah Banas, Douglas Bessette and Hannah Smith. 2019. “Exploring landowners' postconstruction changes in perceptions of wind energy in Michigan." Land Use Policy 82: 754-762.

Musall, Fabian David, and Onno Kuik. 2011. "Local acceptance of renewable energy—A case study from southeast Germany.” Energy Policy 39 (6): 3252-3260.

Parkins, John, Sven Anders, Jürgen Meyerhoff, Monique Holowach and Sonak Patel. 2021. "Landowner survey: Preferences for wind energy development in Alberta." Scholars Portal Dataverse, Available at: https://doi.org/10.7939/DVN/T7KGUZ

Penn, Jerrod M., and Wuyang Hu. 2018. “Understanding Hypothetical Bias: An Enhanced MetaAnalysis." American Journal of Agricultural Economics 100: 1186-1206. 
Rand, Joseph, and Ben Hoen. 2017. "Thirty years of North American wind energy acceptance research: What have we learned?” Energy Research and Social Science 29: 135-148.

Sherren, Kate, John R. Parkins, Taylor Owen and Mikiko Terashima. 2019. "Does noticing energy infrastructure influence public support for energy development? Evidence from a national survey in Canada." Energy Research and Social Science 51: 176-186.

Silvasti, Tiina. 2003. "The cultural model of "the good farmer" and the environmental question in Finland." Agriculture and Human Values 20 (2): 143-150.

Simcock, Neil. 2016. "Procedural justice and the implementation of community wind energy projects: A case study from South Yorkshire, UK." Land Use Policy 59: 467-477.

Sovacool, Benjamin K., and Pushkala Lakshmi Ratan. 2012. "Conceptualizing the acceptance of wind and solar electricity." Renewable and Sustainable Energy Reviews 16 (7): 5268-5279.

Statistics Canada. 2016. Census of Agriculture. Available at: https://www.statcan.gc.ca/eng/ca2016

Syal, Sita M., Yiqing Ding and Erin F. MacDonald. 2020. “Agent-Based Modeling of Decisions and Developer Actions in Wind Farm Landowner Contract Acceptance." Journal of Mechanical Design 142 (9): 091403.

Walker, Chad, and Jamie Baxter. 2017. "Procedural justice in Canadian wind energy development: a comparison of community-based and technocratic siting processes." Energy Research and Social Science 29: 160-169.

Walker, Chad, Jamie Baxter and Danielle Ouellette. 2015. "Adding insult to injury: The development of psychosocial stress in Ontario Wind Turbine communities." Social Science and Medicine 133: 358-365. 
Wiser, Ryan H., and Mark Bolinger. 2019. “2018 Wind Technologies Market Report.” Berkeley, CA: Lawrence Berkeley National Laboratory. Available at: https:/emp.lbl.gov/publications/2018-wind-technologies-market-report Vyn, Richard J. 2018. "Property Value Impacts of Wind Turbines and the Influence of Attitudes toward Wind Energy." Land Economics 94 (4): 496-516. 


\section{Table 1. Attribute levels used in the study}

\begin{tabular}{ll}
\hline Attribute & Levels \\
\hline Location & on your property* \\
- on the other side of your county \\
- on your neighbours' property \\
- also receive some compensation \\
- receive equal compensation amounts as the landowner hosting the turbines \\
- a private utility company* \\
- your municipality \\
- a local cooperative \\
- only the landowners with turbines* \\
- all county residents \\
- only the neighbours who are directly affected \\
- express concern about the project* \\
- express concern and potentially sway \\
- have direct say (e.g. through voting; public meetings) \\
- will be confidential* \\
- will be made available to some affected \\
- will be publicly available
\end{tabular}

* Note: represents status quo within the province. 
Table 2. Respondent sample descriptive statistics

\begin{tabular}{|c|c|c|c|c|}
\hline Variables & $\mathbf{n}$ & Mean (Sd) & Min & $\operatorname{Max}$ \\
\hline \multicolumn{5}{|l|}{ Farm manager characteristics } \\
\hline Gender $(1=$ male, $0=$ female $)$ & 400 & $0.90(0.30)$ & 0 & 1 \\
\hline $\begin{array}{l}\text { Age in years }(1=18-24 ; 2=25-34 ; 3=35-44 ; 4=45-54 \\
5=55-64 ; 6=65-74 ; 7=75 \text { or over })\end{array}$ & 397 & $4.84(1.20)$ & 2 & 7 \\
\hline Primary decision maker for this farm $(1=y e s, 2=$ no $)$ & 401 & $1.03(0.171)$ & 1 & 2 \\
\hline \multicolumn{5}{|l|}{ Political affiliation } \\
\hline Conservative & 281 & $0.701(0.46)$ & 0 & 1 \\
\hline Liberal & 12 & $0.029(0.17)$ & 0 & 1 \\
\hline New Democratic Party (NDP) & 17 & $0.042(0.20)$ & 0 & 1 \\
\hline Green & 4 & $0.009(0.01)$ & 0 & 1 \\
\hline Other & 35 & $0.032(0.18)$ & 0 & 1 \\
\hline Prefer not to say & 56 & $0.130(0.34)$ & 0 & 1 \\
\hline Don’t know & 22 & $0.055(0.23)$ & 0 & 1 \\
\hline \multirow{3}{*}{\multicolumn{5}{|c|}{$\begin{array}{l}\text { Farm structure } \\
\text { Type of Farm (n) } \\
\text { Crops (206), Livestock (47), Mixed (146) }\end{array}$}} \\
\hline & & & & \\
\hline & & & & \\
\hline Size (in acres) & 401 & $\begin{array}{c}2982.53 \\
(4063.85)\end{array}$ & 13 & 30500 \\
\hline $\begin{array}{l}\text { Percent of household income from farming }(1=; 2=1- \\
25 ; 3=26-50 ; 4=51-75 ; 5=76-100)\end{array}$ & 401 & $4.46(0.89)$ & 1 & 5 \\
\hline \multicolumn{5}{|l|}{ Energy perception } \\
\hline $\begin{array}{l}\text { Likelihood of installation of renewables (4-point scale: } \\
1 \text { = Very Likely; } 4 \text { = Very Unlikely) }\end{array}$ & 342 & $2.76(0.901)$ & 1 & 4 \\
\hline $\begin{array}{l}\text { Importance of Alberta's energy sector (5-point scale: } \\
1=\text { Not at all important; 5= Extremely Important) }\end{array}$ & 401 & $4.09(0.812)$ & 1 & 5 \\
\hline $\begin{array}{l}\text { Knowledge about wind energy (4-point scale: } \\
\text { 1=Nothing at all; 4= Quite a bit) }\end{array}$ & 401 & $2.52(0.809)$ & 1 & 4 \\
\hline \multicolumn{5}{|l|}{$\begin{array}{l}\text { Climate change concerns } \\
\quad \text { (5-point scale: } 1=\text { Strongly disagree; } 5=\text { Strongly agree) }\end{array}$} \\
\hline I am very concerned about climate change & 401 & $2.89(1.217)$ & 1 & 5 \\
\hline $\begin{array}{l}\text { We still do not know for sure whether climate change } \\
\text { is real or caused by humans }\end{array}$ & 401 & $3.55(1.179)$ & 1 & 5 \\
\hline Climate change will not be an issue here in Alberta & 401 & $2.73(1.112)$ & 1 & 5 \\
\hline $\begin{array}{l}\text { Alberta adopting renewable energy will help reduce } \\
\text { climate change impacts }\end{array}$ & 401 & $2.52(1.256)$ & 1 & 5 \\
\hline
\end{tabular}


Table 3. Landowner support for energy sources in Canada

\begin{tabular}{llllll}
\hline Energy Source & $\mathrm{n}$ & Mean* & SD & Min & Max \\
\hline Natural gas & 401 & 4.51 & 0.60 & 2 & 5 \\
Oil from oil sands & 400 & 4.43 & 0.71 & 1 & 5 \\
Oil (other than oil sands) & 399 & 4.27 & 0.73 & 1 & 5 \\
Hydroelectricity & 396 & 4.07 & 0.91 & 1 & 5 \\
Bioenergy & 389 & 3.98 & 0.79 & 1 & 5 \\
Solar & 401 & 3.94 & 0.97 & 1 & 5 \\
Geothermal & 383 & 3.92 & 0.86 & 1 & 5 \\
Coal & 394 & 3.62 & 1.13 & 1 & 5 \\
Wind & 397 & 3.44 & 1.21 & 1 & 5 \\
Nuclear & 383 & 3.05 & 1.27 & 1 & 5 \\
\hline
\end{tabular}

* 5-point Likert scale with $1=$ strongly oppose and $5=$ strongly support. 
Table 4. Results of random effects regression models for the vignette attributes and controls for sociodemographic, belief, and knowledge variables

\begin{tabular}{|c|c|c|c|c|c|}
\hline Attributes & Attribute Levels & Model 1 & p-value & Model 2 & p-value \\
\hline \multirow{2}{*}{$\begin{array}{l}\text { Location (ref. your } \\
\text { property) }\end{array}$} & On your neighbours' property & $0.152 *$ & $(0.052)$ & 0.157 & $(0.232)$ \\
\hline & On the other side of your county & $0.382 * * *$ & $(0.000)$ & $0.409 * * *$ & $(0.003)$ \\
\hline \multirow{3}{*}{$\begin{array}{l}\text { Neighbour } \\
\text { Compensation (ref. no } \\
\text { compensation) }\end{array}$} & Receive equal compensation & $0.548 * * *$ & $(0.000)$ & $0.569 * * *$ & $(0.001)$ \\
\hline & $\begin{array}{l}\text { amounts as the landowner } \\
\text { hosting the turbines }\end{array}$ & & & & \\
\hline & Receive some compensation & $0.907 * * *$ & $(0.000)$ & $0.967 * * *$ & $(0.000)$ \\
\hline \multirow{2}{*}{$\begin{array}{l}\text { Ownership structure (ref. } \\
\text { private utility company) }\end{array}$} & Your municipality & $0.282 * * *$ & $(0.000)$ & $0.297 * *$ & $(0.016)$ \\
\hline & A local cooperative & $0.418 * * *$ & $(0.000)$ & $0.453 * * *$ & $(0.000)$ \\
\hline \multirow{2}{*}{$\begin{array}{l}\text { Inclusion (ref. } \\
\text { landowners with } \\
\text { turbines only) }\end{array}$} & $\begin{array}{l}\text { Only neighbours who are } \\
\text { directly affected }\end{array}$ & $0.723 * * *$ & $(0.000)$ & $0.730 * * *$ & $(0.000)$ \\
\hline & All county residents & $0.584^{* * *}$ & $(0.000)$ & $0.602 * * *$ & $(0.000)$ \\
\hline \multirow{2}{*}{$\begin{array}{l}\text { Influence (ref. express } \\
\text { concerns only) }\end{array}$} & $\begin{array}{l}\text { Express concern and potentially } \\
\text { sway }\end{array}$ & $-0.257 * * *$ & $(0.001)$ & $-0.297 * *$ & $(0.016)$ \\
\hline & Have direct say & -0.083 & $(0.285)$ & -0.102 & $(0.366)$ \\
\hline \multirow{2}{*}{$\begin{array}{l}\text { Access to information } \\
\text { (ref. confidential) }\end{array}$} & Will be made available to some & $0.323 * * *$ & $(0.000)$ & $0.371 * * *$ & $(0.003)$ \\
\hline & Will be publicly available & $0.303^{* * *}$ & $(0.000)$ & $0.331 * * *$ & $(0.006)$ \\
\hline \multicolumn{2}{|c|}{ Climate concern (environmental attitude) } & & & $0.659 * * *$ & $(0.006)$ \\
\hline \multicolumn{2}{|c|}{ Community excitement about new wind farms (norm) } & & & $1.878 * * *$ & $(0.000)$ \\
\hline \multicolumn{2}{|c|}{ Experience with wind farms (history) } & & & -0.075 & $(0.338)$ \\
\hline \multicolumn{2}{|l|}{ Age (young) } & & & 0.734 & $(0.225)$ \\
\hline \multicolumn{2}{|c|}{ Knowledge about wind energy } & & & $0.395 * * *$ & $(0.000)$ \\
\hline \multicolumn{2}{|c|}{ Small land holding (farm size) } & & & $0.541^{* *}$ & $(0.032)$ \\
\hline \multicolumn{2}{|l|}{ Conservative political views } & & & $0.574 * *$ & $(0.023)$ \\
\hline \multicolumn{2}{|l|}{ Constant } & $4.377 * * *$ & $(0.000)$ & $2.730 * * *$ & $(0.000)$ \\
\hline \multicolumn{2}{|l|}{ Number of vignettes } & 2406 & & 2226 & \\
\hline \multicolumn{2}{|l|}{ Number of respondents } & 401 & & 371 & \\
\hline \multicolumn{2}{|l|}{ Log. Likelihood } & -10841.88 & & -5237.74 & \\
\hline \multicolumn{2}{|l|}{ Std. dev. random effect } & 2.621 & & 1.933 & \\
\hline
\end{tabular}


St. dev. error

2.028

2.212

Intra-class correlation

0.625

0.605

Notes: Notes: ${ }^{* * *} \mathrm{p}<0.01,{ }^{* *} \mathrm{p}<0.05,{ }^{*} \mathrm{p}<0.1$. Unstandardized coefficients. Standard errors are clustered at the respondent-level. 


\section{Figure 1. Example of a vignette as shown to Landowners}

"There is an opportunity for [your municipality/local cooperative/private utility company] to develop a wind farm [on the other side of your county (over $60 \mathrm{~km}$ away)/on your neighbours' property/on your property]. For projects like this, other residents living nearby will receive [no compensation/some compensation based on their proximity to the turbines/equal compensation amounts as the landowner hosting the turbines]. Only [landowners with turbines/the neighbours who are directly affected/all county residents] will be invited [to express concern about/express concern and potentially sway/have direct say about (e.g. through voting; public meetings)] the project. Meanwhile, details about the lease payments and compensation amounts will be [confidential/available to some affected /publicly available]."

Given this situation and the assumptions stated before, how acceptable or unacceptable does this wind energy development sound to you?

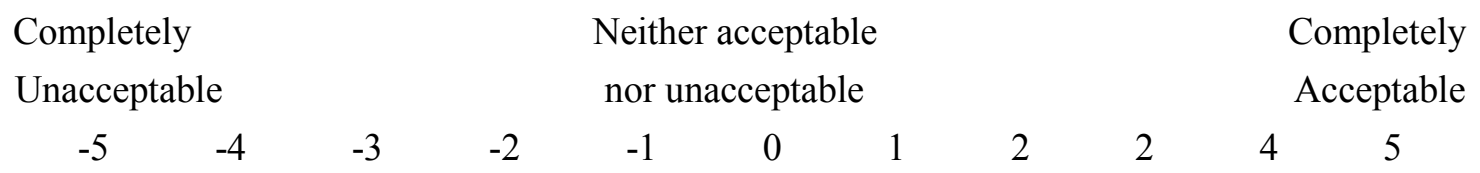


Figure 2. Vignette ratings by stated support for different energy sources, $\mathbf{n}=\mathbf{2 3 5 8}$

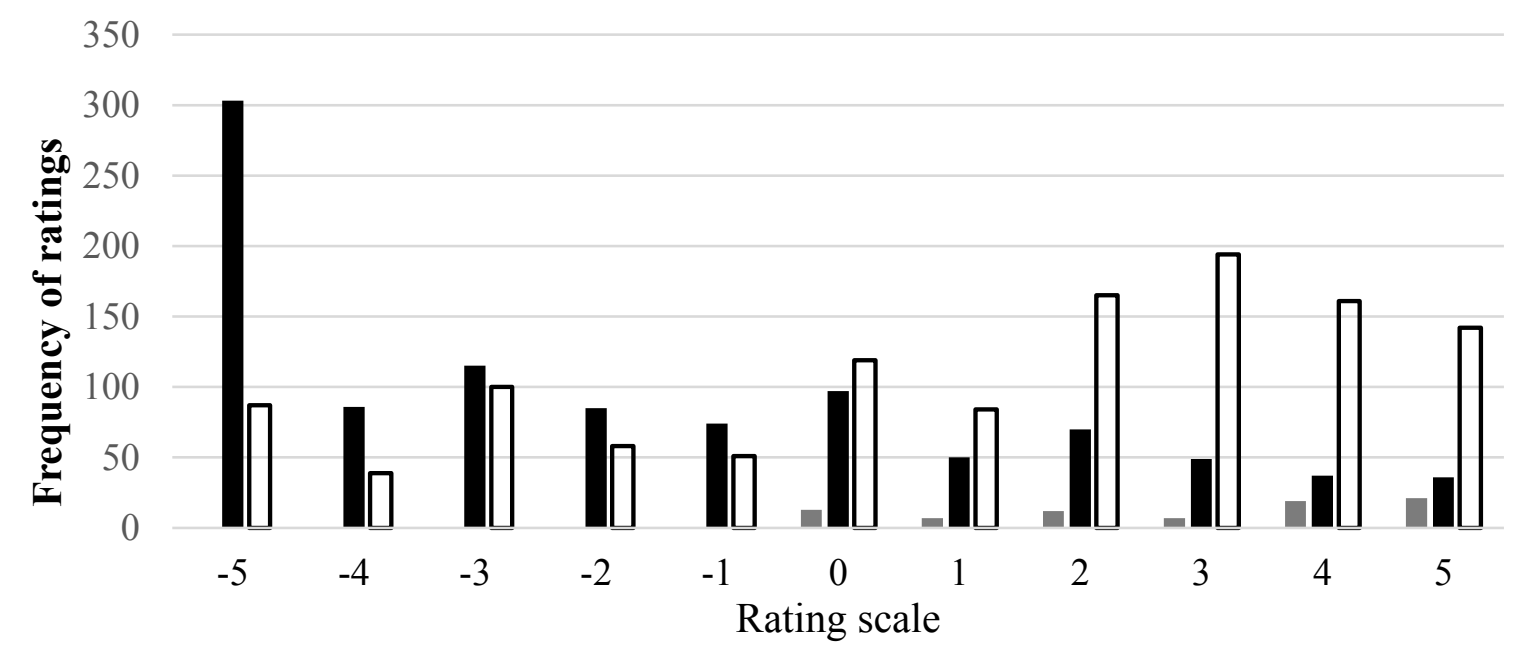

Notes: Vignette ratings are based on an 11-point scale from -5 to +5 where end points were described textually as completely unacceptable to complete acceptable. Solid black indicates landowners that expressed strong (4) or very strong (5) support for oil from oilsands on a 5-point scale; $1=$ completely unacceptable and $5=$ completely acceptable. Grey indicates strong and very strong support for wind energy on the same scale. White bars indicate strong and very strong support for both oil sands and wind energy. The discrepancy in vignette ratings are landowners that did not express support for either of the selected energy sources. 
"There is an opportunity for [your municipality/local cooperative/private utility company] to develop a wind farm [on the other side of your county (over $60 \mathrm{~km}$ away)/on your neighbours' property/on your property]. For projects like this, other residents living nearby will receive [no compensation/some compensation based on their proximity to the turbines/equal compensation amounts as the landowner hosting the turbines]. Only [landowners with turbines/the neighbours who are directly affected/all county residents] will be invited [to express concern about/express concern and potentially sway/have direct say about (e.g. through voting; public meetings)] the project. Meanwhile, details about the lease payments and compensation amounts will be [confidential/available to some affected /publicly available]."

Given this situation and the assumptions stated before, how acceptable or unacceptable does this wind energy development sound to you?

\begin{tabular}{|c|c|c|c|c|c|c|c|c|c|c|}
\hline \multirow{2}{*}{\multicolumn{2}{|c|}{$\begin{array}{l}\text { Completely } \\
\text { Unacceptable }\end{array}$}} & \multicolumn{6}{|c|}{ Neither acceptable } & & \multicolumn{2}{|c|}{ Completely } \\
\hline & & & & nor $\mathrm{n}$ & ep & & & & & ptable \\
\hline-5 & -4 & -3 & -2 & -1 & 0 & 1 & 2 & 2 & 4 & 5 \\
\hline
\end{tabular}




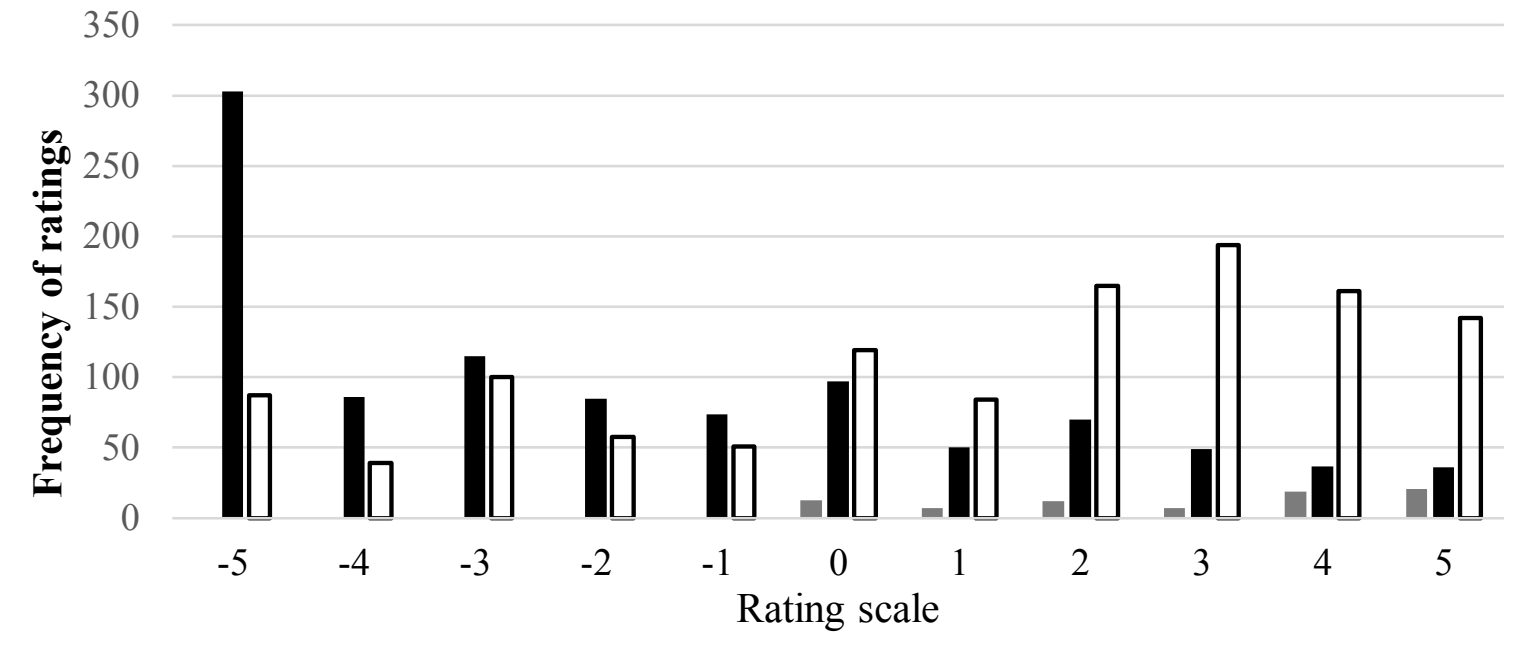

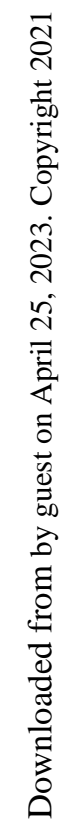

